\title{
Coarse $\mathrm{Nb}_{3} \mathrm{Sn}$ Grain Formation and Phase Evolution During the Reaction of a High Sn Content Internal Tin Strand
}

\author{
C. Scheuerlein, M. Di Michiel, G. Arnau, R. Flükiger, F. Buta, I. Pong, L. Oberli, and L. Bottura
}

\begin{abstract}
The formation of coarse $\mathrm{Nb}_{3} \mathrm{Sn}$ grains in Internal Tin (IT) strands has been studied at the example of a prototype strand with high Sn content. Metallographic examination revealed that the comparatively low critical current density $\left(J_{c}\right)$ of this strand is partly due to the formation of a significant fraction of coarse grained $\mathrm{Nb}_{3} \mathrm{Sn}$ at the periphery of the individual filaments within the subelements. The phase evolution during the reaction heat treatment has been determined in situ by high energy synchrotron X-ray diffraction as well as ex situ by Energy Dispersive $X$-ray Spectroscopy in a Scanning Electron Microscope (SEM) in order to identify the conditions under which the coarse grains form. Similar to what is observed in the tubular type strands, $\mathrm{Nb}_{3} \mathrm{Sn}$ coarse grain formation occurs in the filament areas that had first been transformed into $\mathrm{NbSn}_{2}$ and $\mathrm{Nb}_{6} \mathrm{Sn}_{5}$, prior to $\mathrm{Nb}_{3} \mathrm{Sn}$ formation, and it accounts for an estimated $J_{c}$ reduction of roughly $20 \%$. The amount of $\mathrm{Cu}-\mathrm{Nb}-\mathrm{Sn}$ and $\mathrm{NbSn}_{2}$ that is formed during the heat treatment can be reduced by increasing the temperature ramp rate, while the amount of $\mathrm{Nb}_{6} \mathrm{Sn}_{5}$ formed appears to be hardly influenced by the different heat treatments that have been tested.
\end{abstract}

Index Terms- $\mathrm{Nb}_{3} \mathrm{Sn}$, superconducting wires and filaments.

\section{INTRODUCTION}

I T IS well known that during the reaction heat treatment of $\mathrm{Nb}_{3} \mathrm{Sn}$ strands with high Sn contents, e.g. Internal Tin (IT) or Powder-in-Tube (PIT) strands, several intermediate phases are formed, which decompose again before the final A15 phase is formed. The succession of phases can have a strong influence on the $\mathrm{Nb}_{3} \mathrm{Sn}$ grain size and microchemistry in the fully reacted state. This is best observed in the tubular strand types (Powder-in-Tube (PIT) [1] and Tube Type [2]), where an important fraction of $\mathrm{Nb}_{3} \mathrm{Sn}$ is present in the form of coarse grains. In PIT strands typically $25 \%$ of $\mathrm{Nb}_{3} \mathrm{Sn}$ consist of coarse grains [3] and similar amounts of coarse grain $\mathrm{Nb}_{3} \mathrm{Sn}$ are observed in Tube Type strands [4]. In restack rod processed (RRP) IT

Manuscript received August 01, 2010; accepted September 24, 2010. Date of publication October 28, 2010; date of current version May 27, 2011.

C. Scheuerlein, G. Arnau, I. Pong, L. Oberli, and L. Bottura are with CERN, 1211 Geneva 23, Switzerland (e-mail: Christian.Scheuerlein@cern.ch).

M. Di Michiel is with the European Synchrotron Radiation Facility, 38000 Grenoble, France.

R. Flükiger is with the Group of Applied Physics, University of Geneva, 1211 Geneva 4, Switzerland and also with CERN, 1211 Geneva 23, Switzerland.

F. Buta is with the Group of Applied Physics, University of Geneva, 1211 Geneva 4, Switzerland.

Color versions of one or more of the figures in this paper are available online at http://ieeexplore.ieee.org.

Digital Object Identifier 10.1109/TASC.2010.2082476

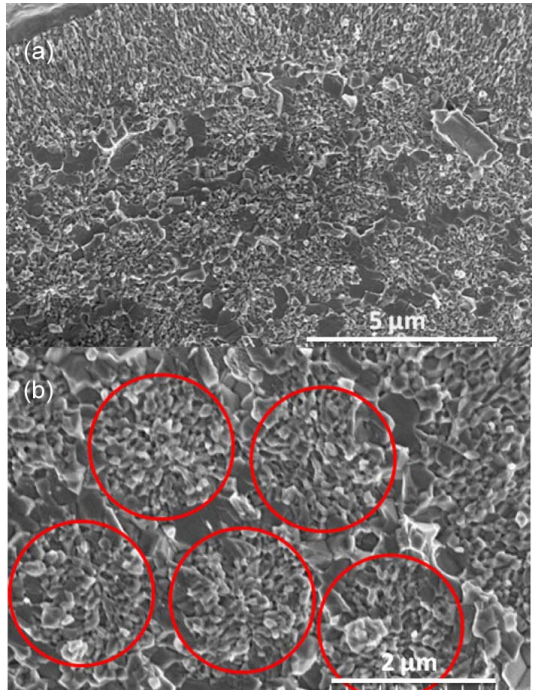

Fig. 1. (a) SEM image of a fractured sample of the B1-63468 strand reacted $50 \mathrm{~h}$ at $660^{\circ} \mathrm{C}$. The coarse grains are present around the location of the original $\mathrm{Nb}$ filaments, as shown by the red circles in (b).

strands, coarse $\mathrm{Nb}_{3} \mathrm{Sn}$ grains are observed too, but their amount with respect to the entire $\mathrm{Nb}_{3} \mathrm{Sn}$ volume is comparatively small [5].

In this article we describe the phase sequence during the reaction heat treatment of a prototype IT strand with high Sn content and its influence on the formation of coarse $\mathrm{Nb}_{3} \mathrm{Sn}$ grains. This prototype strand (in the following referred to as B1-63468) has been produced in the frame of the Next European Dipole conductor development program and does not contain Ta or Ti additions. Its non-Cu critical current density $\left(J_{c}\right)$ remained below $1500 \mathrm{~A} / \mathrm{mm}^{2} @ 4.2 \mathrm{~K}$ at $12 \mathrm{~T}$. For comparison, this value is less than half of the highest $J_{c}$ values obtained routinely for long lengths of Ta or Ti alloyed Internal Sn strands of the RRP design [6].

As revealed by metallographic analysis of fractured samples after reaction of $50 \mathrm{~h}$ at $660^{\circ} \mathrm{C}$ (see Fig 1), one reason for the comparatively low $J_{c}$ of the B1-63468 sample is a comparatively large fraction of coarse grained $\mathrm{Nb}_{3} \mathrm{Sn}$ that is formed around each filament. Under the assumption of a negligible contribution of coarse $\mathrm{Nb}_{3} \mathrm{Sn}$ grains to the current transport, their presence is thought to be partly responsible for the unexpectedly low $J_{c}$ values of the prototype strand.

The phase formation sequence was determined by high energy synchrotron X-ray diffraction measurements performed in situ during reaction. The influence of different ramp rates and 


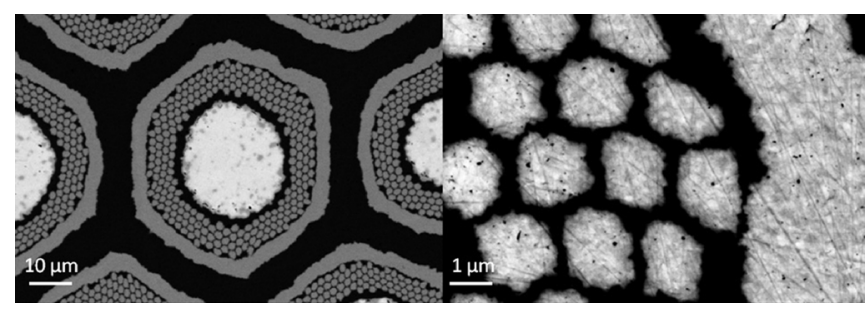

Fig. 2. Cross section of an unreacted B1-63468 sub-element.

long lasting low temperature plateaus on the amount of the different intermetallic phases formed is described. Phase identification with spatial resolution was performed by means of Energy Dispersive X-ray Spectroscopy (EDS) measurements in a Scanning Electron Microscope (SEM).

\section{EXPERIMENTAL}

\section{A. Binary B1-63468 $\mathrm{Nb}_{3} \mathrm{Sn}$ Strand}

A cross section of the prototype B1-63468 strand with 246 subelements is shown in Fig. 2. The strand has a nominal diameter of $1.25 \mathrm{~mm}$ and a $\mathrm{Cu} / \mathrm{non}-\mathrm{Cu}$ ratio of 1.08 . The minimal diameter of the hexagonal subelements is about $53 \mu \mathrm{m}$. Each subelement (nominal composition Nb-53.6, Sn-25.1, Cu-21.3 vol. \%) consists of 246 filaments of about $1.8 \mu \mathrm{m}$ diameter and a diffusion barrier with an approximate thickness of $3.6 \mu \mathrm{m}$. The nominal $\mathrm{Nb} / \mathrm{Sn}$ atomic \% ratio is 3.2 (including the $\mathrm{Nb}$ barrier). The filaments and the barrier are made of pure $\mathrm{Nb}$. The nominal $\mathrm{Cu}$ to $\mathrm{Nb}$ local area ratio is 0.3 .

\section{B. In Situ Synchrotron X-ray Diffraction}

Synchrotron X-ray diffraction measurements were carried out at the ID15B high energy scattering beamline of the European Synchrotron Radiation Facility (ESRF), using a $86.926 \mathrm{keV}$ monochromatic X-ray beam. The high transmission of the high energy X-rays through the highly absorbing metallic samples enables nondestructive diffraction measurements. Debye-Scherrer diffraction patterns were acquired with a Trixell Pixium 4700 detector, with a sample to detector distance of $1004.3 \mathrm{~mm}$. Heating was performed in a dedicated $\mathrm{X}$-ray transparent furnace built at ID15, the sample temperature during diffraction being controlled to $\pm 10{ }^{\circ} \mathrm{C}$.

\section{SEM and EDS}

Strand cross sections were observed with a SEM Leo 430 using a 20-keV electron beam and a solid state diode detector for recording backscattered-electron (BSE) images. The compositional contrast given by the BSE images (regions of increasing atomic number appearing increasingly brighter) allowed the visualization of the constituents of the strand microstructure to a resolution better than $0.1 \mu \mathrm{m}$. An EDS system Oxford Isis 300 with a $\mathrm{Si}(\mathrm{Li})$ detector coupled to the SEM was used in the standardless mode for the quantitative elemental analysis. For the constituents of small size (of the order of the micrometer), the largest regions were targeted to overcome the relatively poor lateral resolution of the EDS point analysis (at least one order of magnitude lower than BSE imaging).
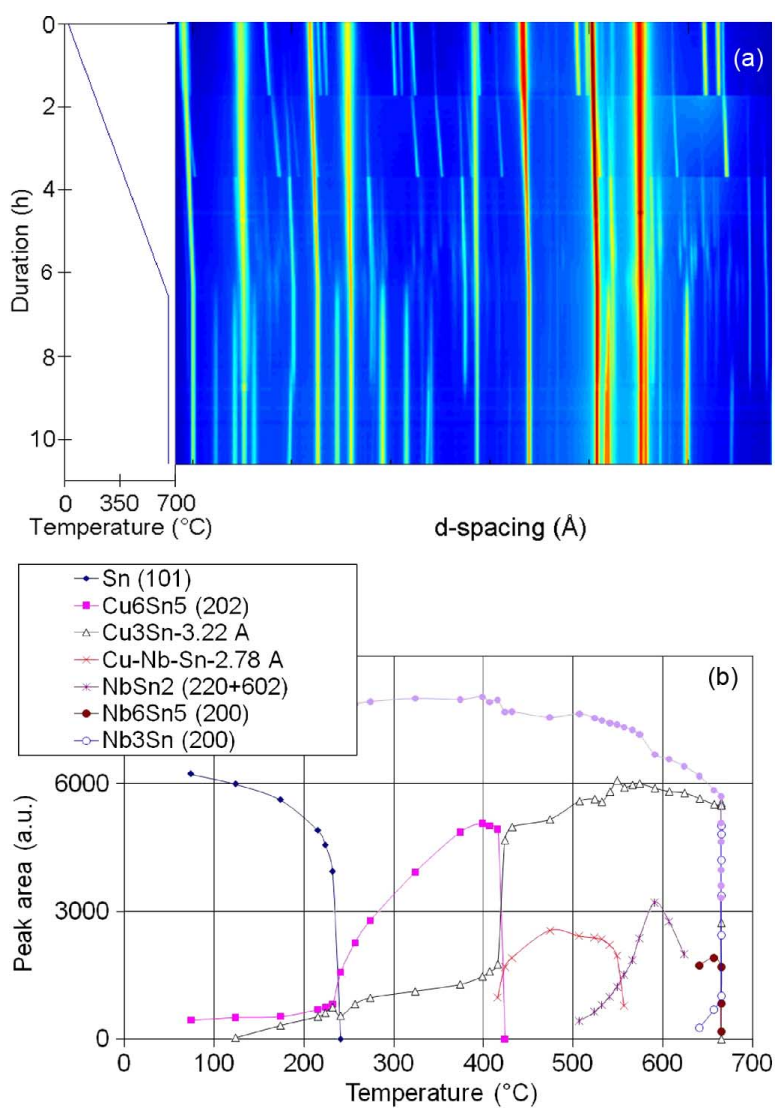

Fig. 3. (a) Variation of the diffraction patterns of the B1-63468 strand during a temperature ramp of $100{ }^{\circ} \mathrm{C} / \mathrm{h}$. The temperature resolution is $8^{\circ} \mathrm{C}$. The evolution of selected peak areas is shown in (b). Peak areas have been arbitrarily scaled in order to fit into the plot.

\section{RESULTS}

\section{A. In Situ Synchrotron X-ray Diffraction up to $665^{\circ} \mathrm{C}$}

Diffraction measurements have been performed in situ during different temperature ramps and at a final plateau at $665^{\circ} \mathrm{C}$. In order to study the influence of the ramp rate, the amounts of the different phases formed during a very fast temperature ramp of $600{ }^{\circ} \mathrm{C} / \mathrm{h}$ have been compared with those formed during a $100^{\circ} \mathrm{C} / \mathrm{h}$ ramp. The influence of long plateaus at lower temperature has been studied during a $100{ }^{\circ} \mathrm{C} / \mathrm{h}$ ramp applied to a sample that had been heat treated in for $314 \mathrm{~h}$ at $200^{\circ} \mathrm{C}$ and $50 \mathrm{~h}$ at $400^{\circ} \mathrm{C}$, prior to the diffraction measurements.

The sequence of diffractograms acquired during the reaction of the B1-63468 strand with a ramp rate of $100^{\circ} \mathrm{C} / \mathrm{h}$ and a subsequent isothermal heat treatment at $665^{\circ} \mathrm{C}$ is presented in the color intensity diagram shown in Fig. 3(a). The corresponding evolution of selected diffraction peak areas is shown in Fig. 3(b).

Before the onset of $\mathrm{Nb}_{3} \mathrm{Sn}$ formation, four intermetallic phases have been identified by comparison with published reference diffraction pattern: $\mathrm{Cu}_{6} \mathrm{Sn}_{5}, \mathrm{Cu}_{3} \mathrm{Sn}, \mathrm{NbSn}_{2}$, and $\mathrm{Nb}_{6} \mathrm{Sn}_{5}$. In addition the diffraction pattern of a presumed $\mathrm{Cu}-\mathrm{Nb}-\mathrm{Sn}$ ternary phase was detected. All these phases have previously been detected during the reaction of $\mathrm{Nb}_{3} \mathrm{Sn}$ strands of the PIT [7], Tube Type [8] and RRP [5] design. The temperature regions where the different intermetallic phases are 

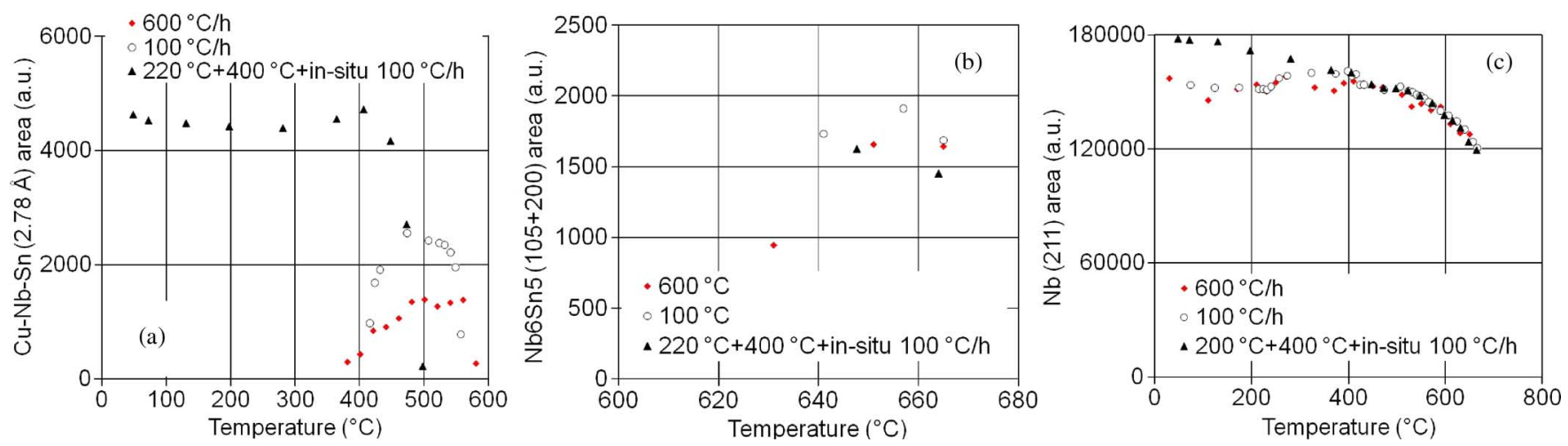

Fig. 4. (a) $\mathrm{Cu}-\mathrm{Nb}-\mathrm{Sn}$ peak with $\mathrm{d}=2.78 \AA$, (b) $\mathrm{Nb}_{6} \mathrm{Sn}_{5}$ (105)+(200), and (c) $\mathrm{Nb}$ (211) peak area evolution during heat treatment of the B1-63468 strand with different ramp rates.

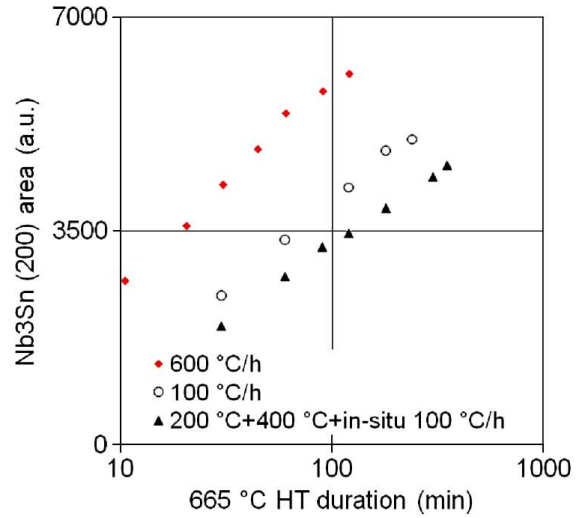

(a)

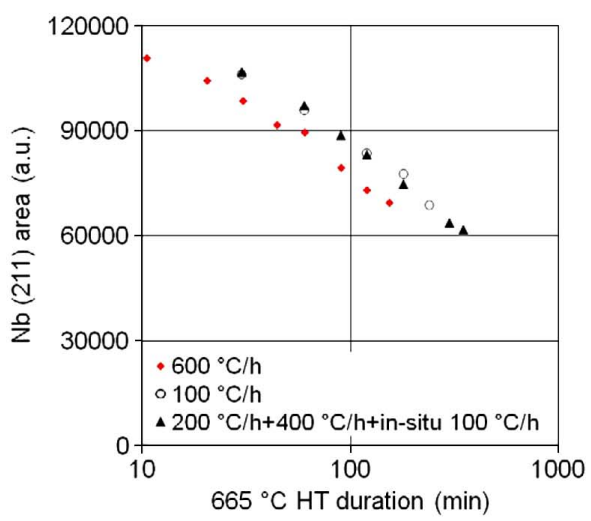

(b)

Fig. 5. Evolution of the $\mathrm{Nb}_{3} \mathrm{Sn}(200)$ and $\mathrm{Nb}$ (211) peak area of the B1-63468 strand during isothermal heat treatment at $665^{\circ} \mathrm{C}$ subsequent to heating with different ramp rates.

detected are similar to those determined by diffraction measurements for the other high $\mathrm{Sn} \mathrm{Nb}_{3} \mathrm{Sn}$ strands [8].

The evolution of selected $\mathrm{Cu}-\mathrm{Nb}-\mathrm{Sn}, \mathrm{Nb}_{6} \mathrm{Sn}_{5}$ and $\mathrm{Nb}$ peak areas during the three different heating ramps $\left(600^{\circ} \mathrm{C} / \mathrm{h}\right.$, $100^{\circ} \mathrm{C} / \mathrm{h}$, and $100{ }^{\circ} \mathrm{C} / \mathrm{h}$ subsequent to $314 \mathrm{~h}$ at $200{ }^{\circ} \mathrm{C}$ and $50 \mathrm{~h}$ at $400{ }^{\circ} \mathrm{C}$ ) is shown in Fig. 4. The ramp rate has a significant influence on the maximum amount of the $\mathrm{Cu}_{6} \mathrm{Sn}_{5}$, $\mathrm{Cu}-\mathrm{Nb}-\mathrm{Sn}$ and $\mathrm{NbSn}_{2}$ formed $\left(\mathrm{Cu}_{6} \mathrm{Sn}_{5}\right.$, and $\mathrm{NbSn}_{2}$ results are not shown in Fig. 4). With the faster temperature ramp, less of these phases are formed. $\mathrm{NbSn}_{2}$ formation can be largely avoided and the amount of $\mathrm{Cu}-\mathrm{Nb}-\mathrm{Sn}$ strongly decreased when heating with $600 \mathrm{C} / \mathrm{h}$. Assuming that the $\mathrm{Nb}$ that is dissolved in the ternary $\mathrm{Cu}-\mathrm{Nb}-\mathrm{Sn}$ phase is not transferred into fine grained $\mathrm{Nb}_{3} \mathrm{Sn}$ later on, it can be concluded that long lasting low temperature plateaus in the temperature range where the ternary $\mathrm{Cu}-\mathrm{Nb}-\mathrm{Sn}$ phase forms can be counterproductive for improving $J_{c}$ of the fully reacted strand.

The $\mathrm{Nb}_{6} \mathrm{Sn}_{5}$ peaks are comparatively small, thus rendering $\mathrm{Nb}_{6} \mathrm{Sn}_{5}$ peak area measurements difficult. Nevertheless it can be concluded from the $\mathrm{Nb}_{6} \mathrm{Sn}_{5}$ peak area measurements shown in Fig. 4(b) that the amount of $\mathrm{Nb}_{6} \mathrm{Sn}_{5}$ is not strongly influenced by the ramp rate.

Above $400{ }^{\circ} \mathrm{C}$, the evolution of the $\mathrm{Nb}(211)$ peak area as a function of temperature is within the experimental error identical for all three temperature ramp rates [see Fig. 4(c)]. The differences in the $\mathrm{Nb}$ (211) areas measured at lower temperatures may be caused by a different spatial distribution of the strongly absorbing $\mathrm{Sn}$ in the subelements of the strand heated for $314 \mathrm{~h}$ at $200^{\circ} \mathrm{C}+50 \mathrm{~h}$ at $400^{\circ} \mathrm{C}$ and in the strands without prior treatment. Variations of the texturing of the strongly cold drawn $\mathrm{Nb}$ precursor could be another explanation. However, to our knowledge $\mathrm{Nb}$ recrystallization at temperatures below $400{ }^{\circ} \mathrm{C}$ has not been reported.

Assuming that above $415{ }^{\circ} \mathrm{C}$, the $\mathrm{Cu}_{6} \mathrm{Sn}_{5}$ decomposition temperature, the $\mathrm{Nb}$ (211) peak area is proportional to the amount of $\mathrm{Nb}$ present in the strand, it can be estimated that in the B1-63469 strand roughly $20 \%$ of $\mathrm{Nb}$ is transformed into $\mathrm{Cu}-\mathrm{Nb}-\mathrm{Sn}, \mathrm{NbSn}_{2}$ and finally $\mathrm{Nb}_{6} \mathrm{Sn}_{5}$, and this part of $\mathrm{Nb}$ is lost for the formation of fine grained $\mathrm{Nb}_{3} \mathrm{Sn}$.

The $\mathrm{Nb}_{3} \mathrm{Sn}$ (200) peak area evolution during the different heat treatments is compared in Fig. 5(a). The results may indicate that the growth of $\mathrm{Nb}_{3} \mathrm{Sn}$ subsequent to a $600{ }^{\circ} \mathrm{C} / \mathrm{h}$ ramp is somewhat faster than the growth following the slower temperature ramps. The onset temperature at which the $\mathrm{Nb}_{3} \mathrm{Sn}$ diffraction pattern is detected when heating with a ramp rate of $100^{\circ} \mathrm{C} / \mathrm{h}$ is about $650{ }^{\circ} \mathrm{C}$.

\section{B. SEM/EDS Results}

Phase analysis with micrometer spatial resolution has been performed on polished strand cross sections, as a complement to the diffraction results. Individual heat treatments of $10 \mathrm{~h}$ at $380^{\circ} \mathrm{C}, 440{ }^{\circ} \mathrm{C}, 490^{\circ} \mathrm{C}$, and $590^{\circ} \mathrm{C}$ have been achieved under 


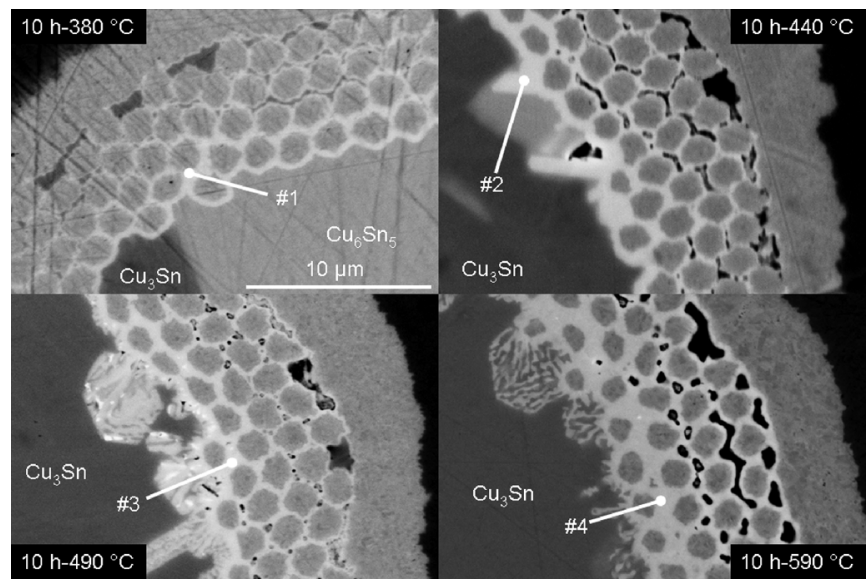

Fig. 6. BE-SEM image of B1-63468 strand cross sections after $10 \mathrm{~h}$ at $380^{\circ} \mathrm{C}$, $440{ }^{\circ} \mathrm{C}, 490{ }^{\circ} \mathrm{C}$, and $590^{\circ} \mathrm{C}$.

TABLE I

ElemENTAL Composition as Determined By EDS AND IDENTIFIEd PHASES

\begin{tabular}{lcc}
\hline \hline & Composition in at.\%* & Main phase identified \\
\hline$\# 1$ & $\mathrm{Cu}-10.4, \mathrm{Nb}-39.0, \mathrm{Sn}-50.6$ & Presumed ternary $\mathrm{Cu}-\mathrm{Nb}-\mathrm{Sn}$ \\
$\# 2$ & $\mathrm{Cu}-18.1, \mathrm{Nb}-17.1, \mathrm{Sn}-64.8$ & Presumed ternary $\mathrm{Cu}-\mathrm{Nb}-\mathrm{Sn}$ \\
$\# 3$ & $\mathrm{Cu}-3.7, \mathrm{Nb}-38.5, \mathrm{Sn}-57.8$ & $\mathrm{NbSn}_{2}+\mathrm{Cu}$ \\
$\# 4$ & $\mathrm{Cu}-5.7, \mathrm{Nb}-50.2, \mathrm{Sn}-44.1$ & $\mathrm{Nb}_{6} \mathrm{Sn}_{5}+\mathrm{Cu}$ \\
\hline \hline
\end{tabular}

* Semiquantitative EDS results of interfilament material overestimate the $\mathrm{Nb}$ content due to the proximity of the $\mathrm{Nb}$ filaments.

vacuum, each with a ramp rate of $60^{\circ} \mathrm{C} / \mathrm{h}$. BSE images of the respective cross sections are shown in Fig. 6.

The elemental compositions determined by EDS in the different cross sections are summarized in Table I. The EDS results overestimate the amount of $\mathrm{Nb}$, due to the proximity of the unreacted $\mathrm{Nb}$ filaments. Nevertheless, in spite of the limited spatial resolution of EDS measurements in the SEM and the comparatively small size of the phases of interest, it is possible to distinguish between the presumed $\mathrm{Cu}-\mathrm{Nb}-\mathrm{Sn}$ ternary phase, $\mathrm{NbSn}_{2}$ and $\mathrm{Nb}_{6} \mathrm{Sn}_{5}$.

After $10 \mathrm{~h}$ at $380{ }^{\circ} \mathrm{C}$ the matrix is partly in the form of $\mathrm{Cu}_{6} \mathrm{Sn}_{5}$ and $\mathrm{Cu}_{3} \mathrm{Sn}$ and the presumed $\mathrm{Cu}-\mathrm{Nb}-\mathrm{Sn}$ ternary phase is detected around the individual filaments. During the $10 \mathrm{~h}-440{ }^{\circ} \mathrm{C}$ treatment most $\mathrm{Cu}_{6} \mathrm{Sn}_{5}$ has been transformed into $\mathrm{Cu}_{3} \mathrm{Sn}$, but a small amount of $\mathrm{Cu}_{6} \mathrm{Sn}_{5}$ is still detected. Since the $\mathrm{Cu}_{6} \mathrm{Sn}_{5}$ decomposition temperature is $415{ }^{\circ} \mathrm{C}$, this indicates that liquid $\mathrm{Sn}$ was present at the end of the $10 \mathrm{~h}-440^{\circ} \mathrm{C}$ treatment, which was retransformed into $\mathrm{Cu}_{6} \mathrm{Sn}_{5}$ upon cool down [7]. EDS analysis indicates that the material with relatively high atomic number around the filaments is still the presumed $\mathrm{Cu}-\mathrm{Nb}-\mathrm{Sn}$ ternary phase. After $10 \mathrm{~h}$ at $490{ }^{\circ} \mathrm{C}$ $\mathrm{NbSn}_{2}$ is detected at the circumference of the filaments closest to the $\mathrm{Sn}$ source, and after the $10 \mathrm{~h}$ at $590{ }^{\circ} \mathrm{C}$ the $\mathrm{NbSn}_{2}$ is transformed into $\mathrm{Nb}_{6} \mathrm{Sn}_{5}$.

\section{DISCUSSION AND CONCLUSION}

The problem of coarse $\mathrm{Nb}_{3} \mathrm{Sn}$ grain formation in the IT strand studied here, which also occurs in the PIT and Tube Type strands, and to a much smaller extent in the OI-ST RRP strand [5], is related to the high $\mathrm{Sn}$ content needed to reach high $J_{c}$ values. To our best knowledge, in low hysteresis loss IT strands with a much higher $\mathrm{Cu} / \mathrm{Sn}$ ratio inside the subelements, the formation of coarse $\mathrm{Nb}_{3} \mathrm{Sn}$ grains has not been reported.

From metallographic examination (see Fig. 6) it can be concluded that, like in the tubular strands, in the B1-63468 strand the $\mathrm{Nb}_{3} \mathrm{Sn}$ formed from the orthorhombic $\mathrm{Nb}_{6} \mathrm{Sn}_{5}$ has much larger grains than the $\mathrm{Nb}_{3} \mathrm{Sn}$ formed by a diffusion process from the cubic $\mathrm{Nb}$, without intermediate $\mathrm{Nb}_{6} \mathrm{Sn}_{5}$ formation. Thus, in order to reduce the amount of coarse $\mathrm{Nb}_{3} \mathrm{Sn}$ in the fully reacted strand, it is necessary to reduce the amount of $\mathrm{Nb}_{6} \mathrm{Sn}_{5}$ that is formed during the reaction treatment.

The temperature ramp rate influences the amount of $\mathrm{Cu}-\mathrm{Nb}-\mathrm{Sn}$ and $\mathrm{NbSn}_{2}$, but does not have a strong influence on the amount of $\mathrm{Nb}_{6} \mathrm{Sn}_{5}$. Therefore, it is concluded that the formation of coarse $\mathrm{Nb}_{3} \mathrm{Sn}$ grains can not be avoided by employing very fast ramp rates. Even if they did lead to a reduction in the quantity of large grains, very fast ramp rates like the $600{ }^{\circ} \mathrm{C} / \mathrm{h}$ studied here can not be easily applied to magnet coils. However, excessively long temperature ramps can be counterproductive and can cause a degradation of $J_{c}$ due to the dissolution of $\mathrm{Nb}$ in the form of the presumed $\mathrm{Cu}-\mathrm{Nb}-\mathrm{Sn}$ ternary phase. Long durations spent in the approximate temperature interval of $350-550^{\circ} \mathrm{C}$, where the $\mathrm{Cu}-\mathrm{Nb}-\mathrm{Sn}$ phase is observed, should be avoided. A detrimental effect of isothermal plateaus on the microchemical homogeneity has also been observed for an IT strand with comparatively high $\mathrm{Cu} / \mathrm{Sn}$ ratio [9].

Several attempts have been made to reduce the amount of coarse grained $\mathrm{Nb}_{3} \mathrm{Sn}$ in PIT strands by varying the subelement layout and composition (use of different precursors, alloying, etc.) [10], but in today's state-of-the-art PIT strands a relatively large amount of coarse $\mathrm{Nb}_{3} \mathrm{Sn}$ grains is still present. In contrast, in IT strands of the RRP design it is possible to strongly limit the $\mathrm{Nb}_{6} \mathrm{Sn}_{5}$ growth and, as a result, only a very small amount of coarse $\mathrm{Nb}_{3} \mathrm{Sn}$ is formed [8].

The formation of $\mathrm{Nb}_{6} \mathrm{Sn}_{5}$ and coarse grained $\mathrm{Nb}_{3} \mathrm{Sn}$ seems to be linked to the Sn content around the filaments in the relevant temperature range, and possibly to the presence of liquid $\mathrm{Sn}$ at the filament periphery. As can be seen in Fig. 6, the closer the $\mathrm{Nb}$ precursor to the $\mathrm{Sn}$ source, the more $\mathrm{Nb}_{6} \mathrm{Sn}_{5}$ (and coarse $\mathrm{Nb}_{3} \mathrm{Sn}$ ) is formed.

Unlike in the tubular strands, the diffusion path lengths and spacing in IT strands can be varied by varying the filament size and the local $\mathrm{Cu}$ to $\mathrm{Nb}$ area ratio (LAR). As compared to high $J_{c}$ IT strands [11], the B1-63468 LAR of 0.3 is relatively high. Therefore, for high Sn strands it is assumed that reducing the LAR is beneficial in order to reduce the amount of coarse $\mathrm{Nb}_{3} \mathrm{Sn}$ volume. As outlined above, if formation of coarse $\mathrm{Nb}_{3} \mathrm{Sn}$ grains could be avoided this could cause a $J_{C}$ increase of roughly $20 \%$ in the B1-63468 strand.

In this article only the formation of coarse $\mathrm{Nb}_{3} \mathrm{Sn}$ grains is addressed as one reason for the comparatively low $J_{c}$ of the B1-63468 strand. Other possible reasons for the comparatively low $J_{c}$ of this strand include the absence of any alloying elements [12] and the Sn distribution within the A15 phase. Both, the microchemical strand homogeneity and the high average $\mathrm{Sn}$ content are important parameters that can strongly influence the 
critical temperature $\left(T_{c}\right)$, the critical field $\left(B_{c 2}\right)$ and, as a result the critical current density [13].

\section{REFERENCES}

[1] H. Veringa, E. M. Hornsveld, and P. Hoogendam, Adv. Cryo. Eng., vol. 30, pp. 813-821, 1984.

[2] E. Gregory, X. Peng, M. Tomsic, M. D. Sumption, and A. Ghosh, " $\mathrm{Nb}_{3} \mathrm{Sn}$ superconductors made by an economical tubular process," IEEE Trans. Appl. Supercond., vol. 19, no. 3, pt. 3, pp. 2602-2605, 2009.

[3] M. Fischer, "Investigation of the relationships between superconducting properties and reaction conditions in powder-in-tube $\mathrm{Nb}_{3} \mathrm{Sn}$ conductors," M.Sc. thesis, University of Wisconsin, Madison, WI, 2002.

[4] V. R. Nazareth, M. D. Sumption, X. Peng, E. Gregory, M. J. Tomsic, and E. W. Collings, "Characterization of the A15 layer growth and microstructure for varying heat treatments $\mathrm{inNb}_{3} \mathrm{Sn}$ tube type composites," IEEE Trans. Appl. Supercond., vol. 18, no. 2, pp. 1005-1009, 2008.

[5] C. Scheuerlein, M. Di Michiel, G. Arnau, and F. Buta, "Phase transformations during the reaction heat treatment of internal tin $\mathrm{Nb}_{3} \mathrm{Sn}$ strands with high Sn content," IEEE Trans. Appl. Supercond., vol. 18, no. 4, pp. 1754-1760, 2008.
[6] J. A. Parrell, Y. Zhang, M. B. Field, and S. Hong, "Development of internal tin $\mathrm{Nb}_{3} \mathrm{Sn}$ conductor for fusion and particle accelerator applications," IEEE Trans. Appl. Supercond., vol. 17, no. 2, pp. 2560-2563, 2007.

[7] M. Di Michiel and C. Scheuerlein, "Phase transformations during the reaction heat treatment of powder-in-tube $\mathrm{Nb}_{3} \mathrm{Sn}$ superconductors," Supercond. Sci. Technol., vol. 20, pp. L55-L58, 2007.

[8] C. Scheuerlein, M. Di Michiel, L. Thilly, F. Buta, X. Peng, E. Gregory, J. A. Parrell, I. Pong, B. Bordini, and M. Cantoni, "Phase transformations during the reaction heat treatment of $\mathrm{Nb}_{3} \mathrm{Sn}$ superconductors," J. Phys.: Conf. Ser., vol. 234, p. 022032, 2010.

[9] C. Scheuerlein, M. Di Michiel, and A. Haibel, "On the formation of voids in $\mathrm{Nb}_{3} \mathrm{Sn}$ superconductors," Appl. Phys. Lett., vol. 90, p. 132510, 2007.

[10] A. Godeke, A. den Ouden, A. Nijhuis, and H. H. J. ten Kate, "State of the art powder-in-tube niobium-tin superconductors," Cryogenics, vol. 48, pp. 308-316, 2008.

[11] M. Field, J. Parrell, Y. Zhang, and S. Hong, "Critical current density in $\mathrm{Nb}_{3} \mathrm{Sn}$ superconducting wire," U.S. Patent US 7368021 B2, May 2008.

[12] R. Flükiger, D. Uglietti, C. Senatore, and F. Buta, "Microstructure, composition and critical current density of superconducting $\mathrm{Nb}_{3} \mathrm{Sn}$ wires ," Cryogenics, vol. 48, pp. 293-307, 2008.

[13] P. J. Lee and D. C. Larbalestier, "Microstructural factors important for the development of high critical current density $\mathrm{Nb}_{3} \mathrm{Sn}$ strand," Cryogenics, vol. 48, pp. 283-292, 2008. 